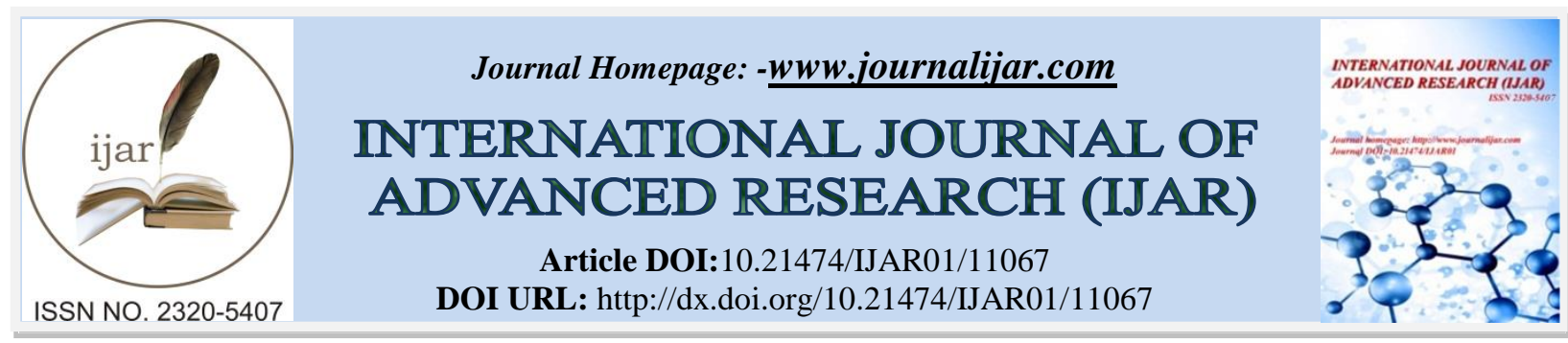

RESEARCH ARTICLE

\title{
PRODUCTION AND CHARACTERIZATION OF COLORING LIQUIDS FOR DENTAL ZIRCONIA FRAMEWORKS
}

\author{
Guray Kaya ${ }^{1}$, Mesut Kok ${ }^{1}$, Busra Gunhan ${ }^{1}$, H. Bogac Poyraz ${ }^{2}$ and Rasim Ceylantekin ${ }^{1}$ \\ 1. Kütahya Dumlupınar University, Evliya Çelebi Campus, Faculty of Engineering, Department of Metallurgical \\ and Materials Engineering, Kütahya 43100, Turkey. \\ 2. Eskişehir Technical University, İki Eylül Campus, Faculty of Engineering, Department of Materials Science \\ and Engineering, Eskişehir 26555, Turkey.
}

\section{Manuscript Info}

Manuscript History

Final Accepted: 05 May 2020

Published: June 2020

Key words:-

Coloring Liquid, Dental Zirconia,

Zirconia Framework, Characterization
Received: 01 April 2020

\begin{abstract}
The coloring of the dental zirconia prostheses is performed by immersing the pre-sintered zirconia framework in the coloring liquid and waiting for a while. There are various problems that dental prosthesis laboratories experience regarding coloring processes. The most important of these is that the desired color can not be obtained in the dental zirconia framework. This may be due to the different density and porosity values of the zirconia frameworks prepared from different commercial zirconia blocks, the thickness of the framework or the unstable coloring liquids. In the present study, it was aimed to produce coloring liquids suitable for Zirmax brand dental zirconia blocks and characterization of zirconia samples that were colored using these liquids. For this purpose; coloring liquids were produced by dissolving different metal salts, pure water and two different organic solvents. Zirconia samples are colored by immersing the samples into prepared coloring liquids. The colored zirconia samples were sintered at $1500{ }^{\circ} \mathrm{C}$ for 2 hours and then the colors of the samples were visually determined by a specialist dental technician. Crystallographic analyzes of zirconia frameworks were performed with X-ray diffraction (XRD) technique. Microstructures of zirconia samples were examined by scanning electron microscope (SEM). According to the color results of the zirconia samples that were analyzed visually, the coloring liquids were successfully produced in accordance with the Ivoclar Vivadent IPS e.max Ceram Dentin A-D color scale.
\end{abstract}

Copy Right, IJAR, 2020,. All rights reserved.

\section{Introduction:-}

Zirconia $\left(\mathrm{ZrO}_{2}\right)$ stabilized with $3 \mathrm{~mol} \%$ yttrium oxide (3Y-TZP) is currently used in dentistry for the fabrication of crowns, fillings, bridges, dental implant abutments and fixed partial dentures as it provides excellent biocompatibility, as well as showing superior strength and toughness in dentistry [1-2]. The production of these zirconia-based dental frameworks is done by milling full or partial sintered blocks using Computer-aided design / Computer-aided production (CAD / CAM) system. The purpose of developing this system is to produce higher quality products of dental zirconia restorations and to obtain these dental products at a more relevant cost [3]. Therefore, some attempts have been made to change the color of Y-TZP ceramics to capture the natural appearance 
of the teeth [4]. The most common coloring method is the immersion of the $\mathrm{ZrO}_{2}$ prosthesis, which is milled from a white and pre-sintered zirconia block, into the coloring liquid or application of the coloring liquid on the zirconia framework using a brush. This coloring process is an advantage in terms of time and aesthetics [5-6-7].

In the study of Tabatabaian et al., the effects of the thickness values of monolithic zirconia ceramics on the final product color had been investigated, and therefore, the pellets produced by transparent monolithic zirconia powders at different thickness values (0.7, 0.9 and $1.1 \mathrm{~mm}$ ) obtained from two different manufacturers (DDcubex, CopraSmile), were colored in a coloring liquid corresponding to the A4 scale and CIE L*a*b* values were measured. Based on their study findings, they stated that the thickness of zirconia was effective on the color of the final product. Researchers have determined that zirconia ceramic thickness should be $0.9 \mathrm{~mm}$ in order to obtain a color that is acceptable in terms of application (8). Kaplan et al. produced samples of dental zirconia powders, which were made semi-stabilized with mol 3\% yttria, in disc form, and they colored these samples in coloring liquids that were prepared using $\mathrm{NiCl}_{2}, \mathrm{MoCl}_{3}$ and $\mathrm{NiCl}_{2}+\mathrm{MoCl}_{3}$ metal salts in different concentrations (Weight. $0.1 \%, 0.25 \%$ and $0.5 \%$ ) for different waiting times $(5,30,60$ seconds), and they examined the effects of the applied process on the mechanical properties of the discs, such as micro hardness, fracture toughness, flexural strength and rate of attrition, and their final colors. Their results revealed that the concentration of coloring liquids had an effect on the final color, while the waiting time in these liquids did not have a significant effect on the final color formation [9].In the study of Ozturk et al., it was observed that the products with different sample thicknesses exposed to coloring liquid had different colors obtained after repeated firing process. They used DC-Zircon and IPS e.max Press branded zirconia framework in their study. With the increase in the thickness of the ceramic, there was a significant decrease in the $\mathrm{L}^{*}$ value of the DC-Zircon branded framework and an increase in the $\mathrm{a}^{*}$ value, while there was no significant change in the $b^{*}$ value. While IPS e.max Press branded framework showed significant decreases in $L^{*}$ value, they found an increase in $\mathrm{a}^{*}$ and $\mathrm{b}^{*}$ values [10]. In the study of Kao et al., they observed that coloring liquids containing different amounts of iron oxide formed a color spectrum on the zirconia frameworks, ranging from yellow to red [11]. In the study of Wen et al. using $\mathrm{CeO}_{2}$ and $\mathrm{Er}_{2} \mathrm{O}_{3}$ colorants, they found that these colorant species went from yellow to green and yellow to red on the zirconia framework [12]. In their study, Lee et al. demonstrated that the brand of the zirconia block used was effective on the color of the final product [13]. In the study conducted by Son et al, it was noted that the color differences in the final product depended on the thickness of the framework, as well as the block brand [14]. Due to the different porosity and density values of different brand zirconia frameworks, even if coloring is performed with the same coloring liquid, obtaining different results creates a complicated situation in terms of coloring zirconia frameworks, and this situation is a factor that limits the use of coloring liquids in practice. In the present study, the coloring liquids suitable for Zirmax brand dental zirconia blocks were produced and it was aimed to characterize of zirconia samples colored using these liquids.

\section{Materials and Method:- \\ Preparation of Zirconia Pellets}

Ready-to-press 3Y-TZP zirconium oxide powder and a $13 \mathrm{~mm}$ diameter press mold were used for preparing zirconia pellets. In order to see the effects of zirconia samples with different thickness on the final color, $0.15,0.4$ and $1.5 \mathrm{~g}$ zirconia powder were pressed at 500 PSI, respectively. In addition, $0.4 \mathrm{~g}$ zirconia powder was shaped by applying 250 PSI pressure to determine the effect of the forming pressure difference on the final color. After the forming process, the final pressing of all samples was done with cold isostatic press (CIP) at 2000 bar. According to the firing program presented in Table 1, zirconia pellets with CIP treatment were subjected to binder removal and presintering processes and they were made ready for coloring.

Table 1:- Pre-sintering program of zirconia samples.

\begin{tabular}{|c|c|c|c|c|c|c|c|c|}
\hline $\begin{array}{c}\text { Program } \\
\text { Code }\end{array}$ & 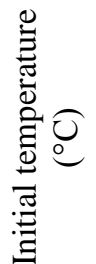 & 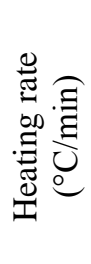 & 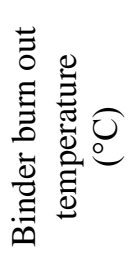 & 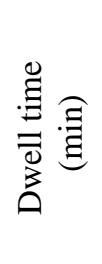 & 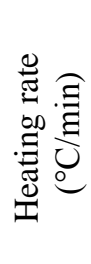 & 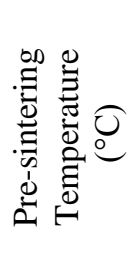 & $\stackrel{\stackrel{\Xi}{\Xi}}{\stackrel{\Xi}{\Xi}} \underset{\Xi}{\Xi}$ & 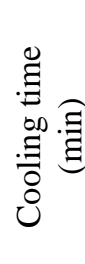 \\
\hline PS-1 & 25 & 0.5 & 700 & 180 & 5 & 900 & 180 & 175 \\
\hline
\end{tabular}




\section{Preparation of Single-Unit Zirconia Frameworks in Tooth Form}

Zirmax brand dental zirconia blocks (produced by Seramdent Dental Ceramics and Nanomaterials Ltd., Eskisehir / Turkey) were used for the preparation of single-unit zirconia frameworks in tooth form where coloring liquids were applied. Blocks were shaped using a milling device with CAD / CAM system.

\section{Preparation of Coloring Liquids}

In the preparation of coloring liquids, 5 different coloring salts (CS1-CS5) and distilled water, organic solvent-1 (OS1) and organic solvent-2 (OS2) were used (Table 2). Initially, the color after using only coloring salts in increasing amounts was determined. Then, three different liquids were prepared by dissolving $0.01 \mathrm{~g} / \mathrm{ml} \mathrm{CS} 1 \mathrm{in}$ three different solvents (distilled water, distilled water + OS1 and distilled water + OS2) in order to examine the effects of solvents used on liquid properties. Finally, 37 different coloring liquids were prepared for A series, 14 for B series, 118 for $\mathrm{C}$ series and 35 for D series using coloring salts, distilled water and OS2 according to Table 3.

Table 2:- Raw materials and their properties used for the preparation of coloring liquids.

\begin{tabular}{|l|c|}
\hline \multicolumn{1}{|c|}{ Raw materials } & Brand and Purity \\
\hline CS1 & MERCK \\
\hline CS2 & Rare Metal Compounds, 99.9\% \\
\hline CS3 & Unknown, 99\% \\
\hline CS4 & Unknown, 99\% \\
\hline CS5 & ZAG Chemistry, 98\% \\
\hline Distilled water & - \\
\hline OS1 & MERCK \\
\hline OS2 & A.D.R. Group \\
\hline
\end{tabular}

Table 3:- Salts and solvents used for the preparation of coloring liquids.

\begin{tabular}{|c|c|c|c|c|c|c|c|}
\hline \multirow{2}{*}{$\begin{array}{l}\text { Receipt } \\
\text { Code }\end{array}$} & \multicolumn{7}{|c|}{ Raw materials } \\
\hline & CS1 & $\mathrm{CS} 2$ & CS3 & CS4 & CS5 & $\begin{array}{l}\text { Distilled } \\
\text { water }\end{array}$ & OS2 \\
\hline B1 & + & - & - & - & - & + & + \\
\hline B2 & + & - & - & - & - & + & + \\
\hline B3 & + & - & - & - & - & + & + \\
\hline B4 & + & - & - & - & - & + & + \\
\hline A1 & + & + & - & - & - & + & + \\
\hline A2 & + & + & - & - & - & + & + \\
\hline A3 & + & + & - & - & - & + & + \\
\hline A3.5 & + & + & - & - & - & + & + \\
\hline A4 & + & + & + & + & - & + & + \\
\hline $\mathrm{C} 1$ & + & - & + & - & + & + & + \\
\hline $\mathrm{C} 2$ & + & - & + & - & + & + & + \\
\hline $\mathrm{C} 3$ & + & - & + & - & + & + & + \\
\hline $\mathrm{C} 4$ & + & - & + & - & + & + & + \\
\hline D2 & + & + & + & - & + & + & + \\
\hline D3 & + & + & + & - & + & + & + \\
\hline D4 & + & - & + & - & + & + & + \\
\hline
\end{tabular}

According to the recipes, organic solvents were added to the $20 \mathrm{ml}$ beaker with a total liquid amount of $10 \mathrm{ml}$ and mixed by the aid of a magnetic stirrer at $500 \mathrm{rpm}$. Colorized salts weighed separately were added into the beaker in the proportions specified in the recipe and mixed until a clear liquid was obtained. The coloring liquids obtained afterwards were stored in a plastic tube.

\section{Coloring of Zirconia Samples}

Coloring process was performed by immersing the samples in the coloring liquid and waiting for the desired time. In order to determine the effect of the holding time in the coloring liquid on the final color, the products in the form of pellets, which were subjected to pre-sintering, were colored in two different coloring liquids (A1 and A3) for 15 
seconds and 60 seconds. The coloring of zirconia samples prepared in tooth form was done by keeping them for 60 seconds in the liquid. All the colored products were subjected to the final sintering process according to the program presented in Table 4.

Table 4:- Final sintering program of zirconia samples.

\begin{tabular}{|c|c|c|c|c|c|}
\hline Name of program & 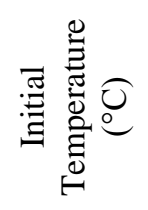 & 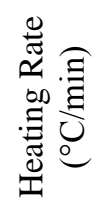 & 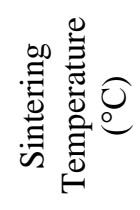 & 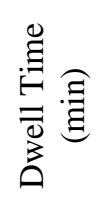 & 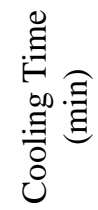 \\
\hline Final sintering & 25 & 10 & 1500 & 120 & 295 \\
\hline
\end{tabular}

\section{Characterization}

Crystalline phases formed in colored zirconia samples were detected by using Rigaku brand Rint 2000 model X-Ray Diffraction (XRD) device with $\mathrm{CuK} \alpha 1$ radiation. Microstructural analysis of the final sintered samples was performed using FEI NovaNanoSEM650 Brand Scanning Electron Microscope with field diffusion electron gun (FEG) in Kütahya Dumlupınar University ILTEM. Density measurement of zirconia samples was done with Archimedes principle and calculated according to the formula below.

Bulk Density $=\frac{\mathrm{W} 1}{(\mathrm{~W} 2-\mathrm{W} 3)} \times \mathrm{P}_{\text {water }}$

W1: Dry weight of sample

W2: Suspended weight of sample in water

W3: Wet weight of sample

$\mathrm{P}_{\text {water: }}$ : Density of water;

Color analysis of single crown zirconia samples produced by using Zirmax brand zirconia block were performed by Dt. Saim Güler in accordance with IPS e.max Ceram Dentin A-D color scale. Color analyzes were carried out between 12:00 and 14:00 hours, in sunny weather, on a gray ground and using a lighting device that provides 5500K daylight support.

\section{Results:-}

When three different liquids prepared to examine the effects of solvents used on liquid properties were examined after 15 days, precipitation was observed in distilled water and distilled water + OS1 containing liquids, while no precipitation was observed in the distilled water + OS2 containing coloring liquid. It was determined that the coloring liquids with precipitation were blurred, and the liquid containing OS2 preserved the clarity as in the day it was produced (Figure 1).

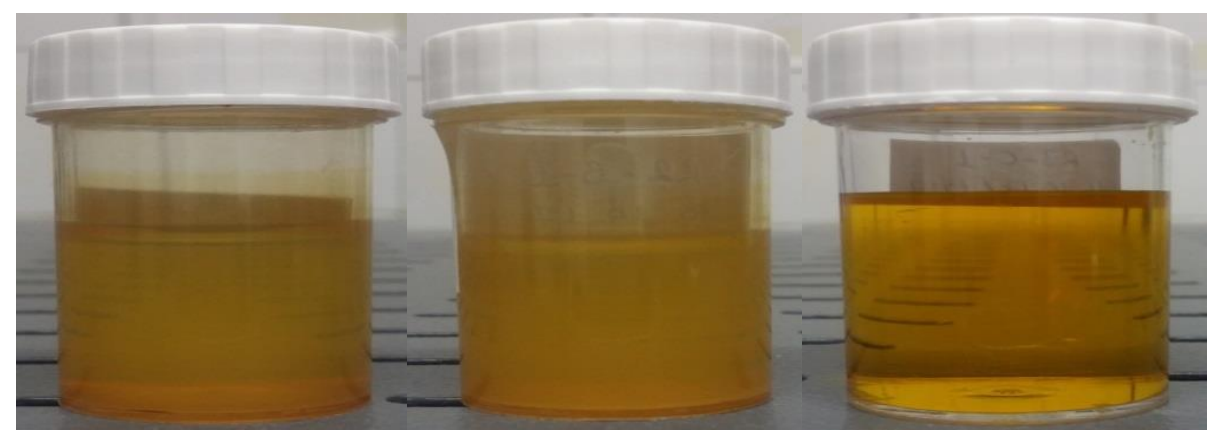

Figure 1:- Images of only distilled water (left), distilled water + OS1 (middle) and distilled water + OS2 (right) liquids after 15 days.

The shelf life of the coloring liquids used in dental prosthesis laboratories and their stability after preparation are extremely important in terms of color. Therefore, it was determined that it would be better to use OS2 in the preparation of coloring liquids. The colors of the zirconia pellets became darker, as expected, due to the use of 
coloring salts in increasing amounts alone (Figure 2 - Figure 6). According to these results, it was possible to determine the amount of coloring salts that should be used to reach the IPS e.max Ceram Dentin A-D scale.

\begin{tabular}{|c|c|c|c|c|}
\hline $\begin{array}{c}\text { Amount of } \\
\text { Coloring Salt } \\
(\mathrm{g} / \mathrm{ml})\end{array}$ & 0.001 & 0.01 & 0.05 & 0.1 \\
\hline $\begin{array}{c}\text { Colored and } \\
\text { sintered pellets }\end{array}$ & & & & \\
\hline
\end{tabular}

Figure 2:- Colored pellets prepared by using CS1-coded salt.

\begin{tabular}{|c|c|c|c|c|c|}
\hline $\begin{array}{c}\text { Amount of } \\
\text { Coloring Salt } \\
(\mathrm{g} / \mathrm{ml})\end{array}$ & 0.001 & 0.01 & 0.05 & 0.1 & 1 \\
\hline $\begin{array}{c}\text { Colored and } \\
\text { sintered pellets }\end{array}$ & & & & & \\
\hline
\end{tabular}

Figure 3:- Colored pellets prepared by using CS2-coded salt.

\begin{tabular}{|c|c|c|c|c|}
\hline $\begin{array}{c}\text { Amount of } \\
\text { Coloring Salt } \\
(\mathrm{g} / \mathrm{ml})\end{array}$ & 0.001 & 0.01 & 0.05 & 0.1 \\
\hline $\begin{array}{c}\text { Colored and } \\
\text { sintered pellets }\end{array}$ & & & & \\
\hline
\end{tabular}

Figure 4:- Colored pellets prepared by using CS3-coded salt.

\begin{tabular}{|c|c|c|c|c|}
\hline $\begin{array}{c}\text { Amount of } \\
\text { Coloring Salt } \\
(\mathrm{g} / \mathrm{ml})\end{array}$ & 0.001 & 0.01 & 0.05 & 0.1 \\
\hline $\begin{array}{c}\text { Colored and } \\
\text { sintered pellets }\end{array}$ & & & & \\
\hline
\end{tabular}

Figure 5 :- Colored pellets prepared by using CS4-coded salt.

\begin{tabular}{|c|c|c|}
\hline $\begin{array}{c}\text { Amount of Coloring Salt } \\
(\mathrm{g} / \mathrm{ml})\end{array}$ & 0.001 & 0.01 \\
\hline & & \\
Colored and sintered pellets & & \\
\hline
\end{tabular}

Figure 6:- Colored pellets prepared by using CS5-coded salt. 
When the cross section surface of zirconia pellets colored at 15 and 60 seconds and sintered is examined, the color absorption has been observed to increase due to the raised coloration time (Figure 7). Therefore, it was considered to color zirconia dental prosthesis materials for 60 seconds for a homogeneous coloring.

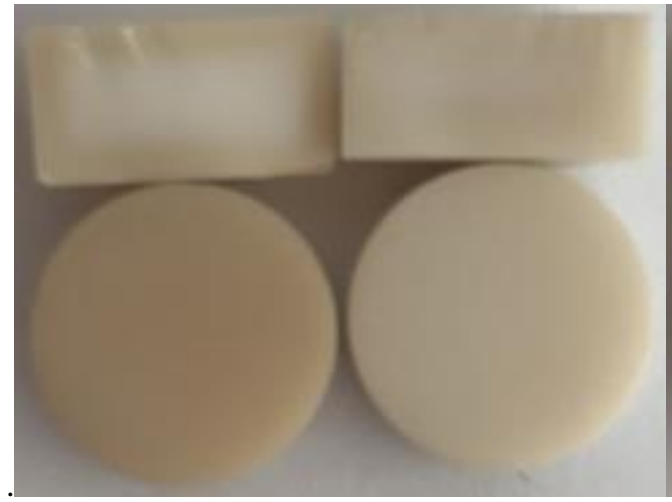

(a)

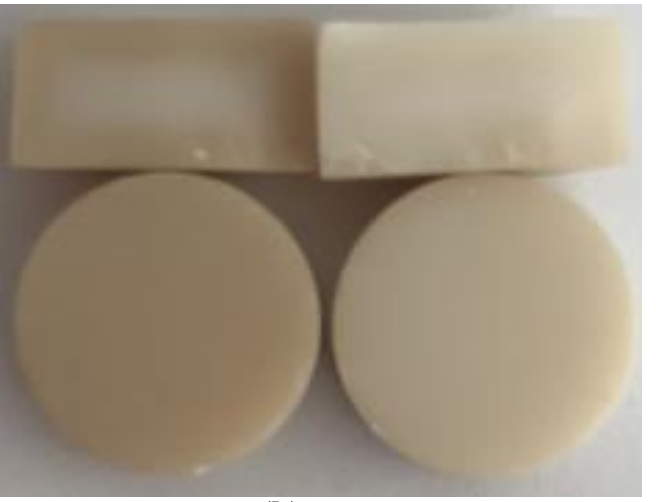

(b)

Figure 7:- a) Pellets colored in two different coloring liquids (A1 and A3) for 15 seconds, b) Pellets colored in two different coloring liquids (A1 and A3) for 60 seconds.

The densities of the pellets produced at different weights and pressure values and those subjected to pre-sintering are presented in Table 5.

Table 5:- Density values of pre-sintered pellets produced at different weights and pressure.

\begin{tabular}{|l|c|}
\hline Zirconia pellets & Density $\left(\mathrm{g} / \mathrm{cm}^{3}\right)$ \\
\hline 0.4 gram / 250 PSI & 3.14 \\
\hline 0.4 gram / 500 PSI & 3.19 \\
\hline 0.15 gram / 500 PSI & 3.19 \\
\hline 1.5 gram / 500 PSI & 3.19 \\
\hline
\end{tabular}

According to the density results, an increase in density value was observed with increasing press pressure, while the density did not change with increasing pellet thickness. This is due to the better packaging of zirconia powders due to the increase in press pressure.

Although they were colored at the same time (60 seconds), it was found that the colors of zirconia pellets with different weight and thickness were changed. The color obtained as a result of increasing the thickness of the sample had been darkened (Figure 8 and Figure 9). Although all the samples had the same density $\left(3.19 \mathrm{~g} / \mathrm{cm}^{3}\right)$, the relevant color darkening was due to the increase in the distance traveled by the light in the zirconia sample.

\begin{tabular}{|c|c|c|c|c|}
\hline Color series & B1 & B2 & A2 & \\
\hline $\begin{array}{c}\text { Colored and } \\
\text { sintered pellets }\end{array}$ & & & & \\
& & & & \\
\end{tabular}

Figure 8:- Image of pellets produced at 0.15 gram with 500 PSI pressure and colored in B1, B2, A2 and A3 coloring liquids. 


\begin{tabular}{|c|c|c|c|c|}
\hline Color series & B1 & B2 & A2 & \\
\hline $\begin{array}{c}\text { Colored and } \\
\text { sintered pellets }\end{array}$ & & & & \\
& & & & \\
\hline
\end{tabular}

Figure 9:- Image of pellets produced at 1.5 gram with 500 PSI pressure and colored in B1, B2, A2 and A3 coloring liquids.

It was determined that the color of samples was lightened with increasing pressure value used in shaping zirconia samples (Figure 10 and Figure 11). This is due to the increase in the density of the sample with increasing press pressure, in other words, due to lower absorption of coloring liquid as a result of the decrease in the amount of porosity in the sample.

\begin{tabular}{|c|c|c|c|c|}
\hline Color series & B1 & B2 & A2 & A3 \\
\hline & & & & \\
$\begin{array}{c}\text { Colored and } \\
\text { sintered pellets }\end{array}$ & & & & \\
& & & & \\
\hline
\end{tabular}

Figure 10:- Image of pellets produced at 0.4 gram with 250 PSI pressure and colored in B1, B2, A2 and A3 coloring liquids.

\begin{tabular}{|c|c|c|c|c|}
\hline Color series & B1 & B2 & A2 & \\
\hline \\
$\begin{array}{c}\text { Colored and } \\
\text { sintered pellets }\end{array}$ & & & & \\
& & & & \\
\end{tabular}

Figure 11:- Image of pellets produced at 0.4 gram with 500 PSI pressure and colored in B1, B2, A2 and A3 coloring liquids.

According to the findings of the visual analysis applied to the zirconia samples that were prepared in the form of teeth, it was determined that all the color series A, B, C and D in the IPS e.max Ceram Dentin AD scale could be obtained successfully with the coloring liquids prepared according to Table 3 (Figure 12-Figure 15).

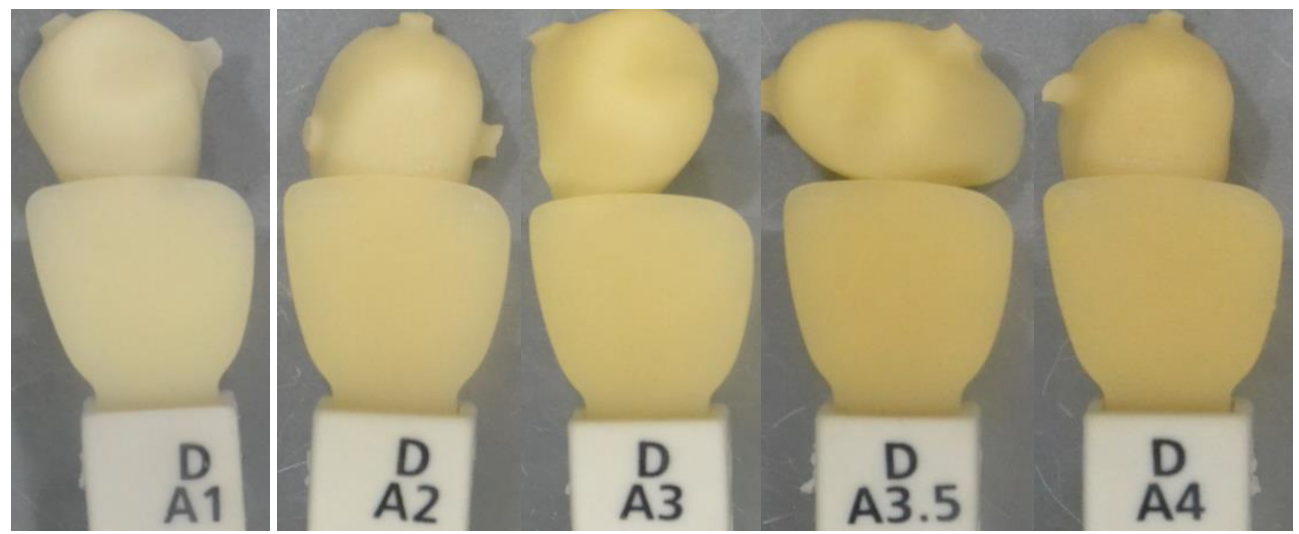

Figure 12:- Samples for A-series according to IPS e.max Ceram Dentin A-D scale. 


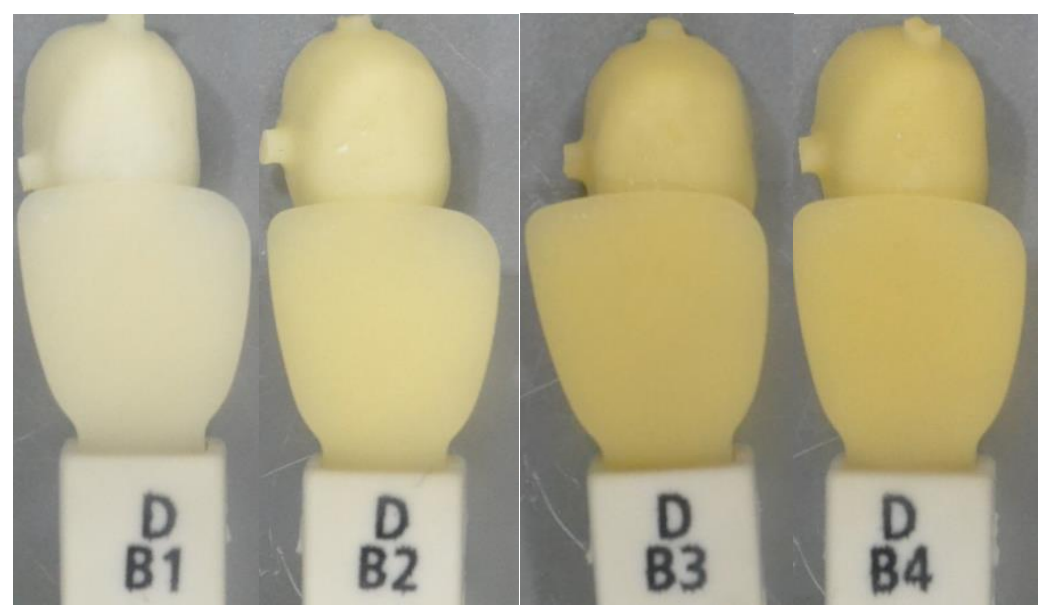

Figure 13:- Samples for B-series according to IPS e.max Ceram Dentin A-D scale.

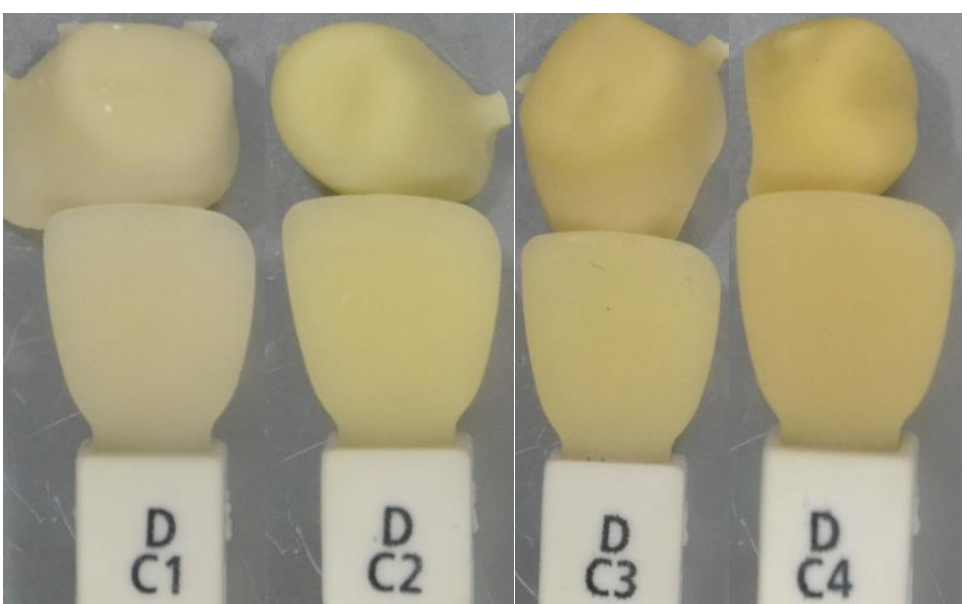

Figure 14:- Samples for C-series according to IPS e.max Ceram Dentin A-D scale.

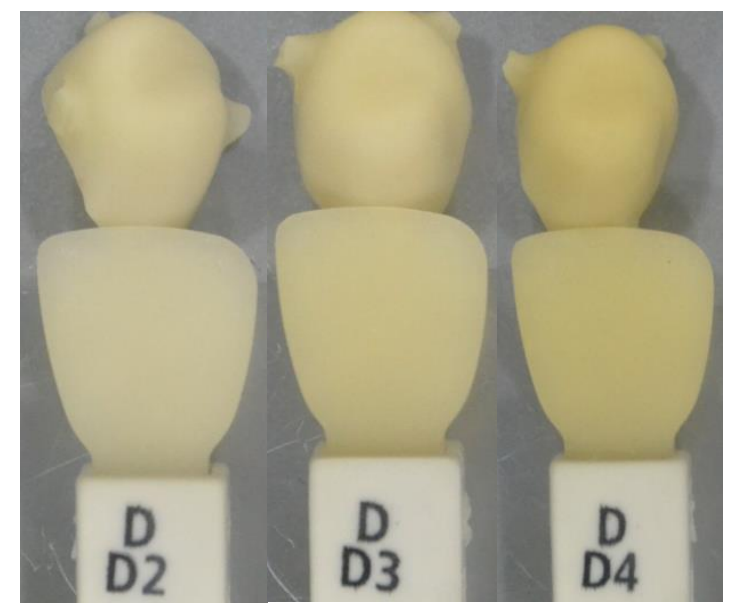

Figure 15:- Samples for D-series according to IPS e.max Ceram Dentin A-D scale.

The results of XRD analysis applied to zirconia samples in colored tooth form are presented in Figure 16-Figure 19. According to the results of XRD analysis, it was determined that the crystal phases in all samples were tetragonal zirconia and coloring liquids had no effect on the crystal structure of zirconia. 


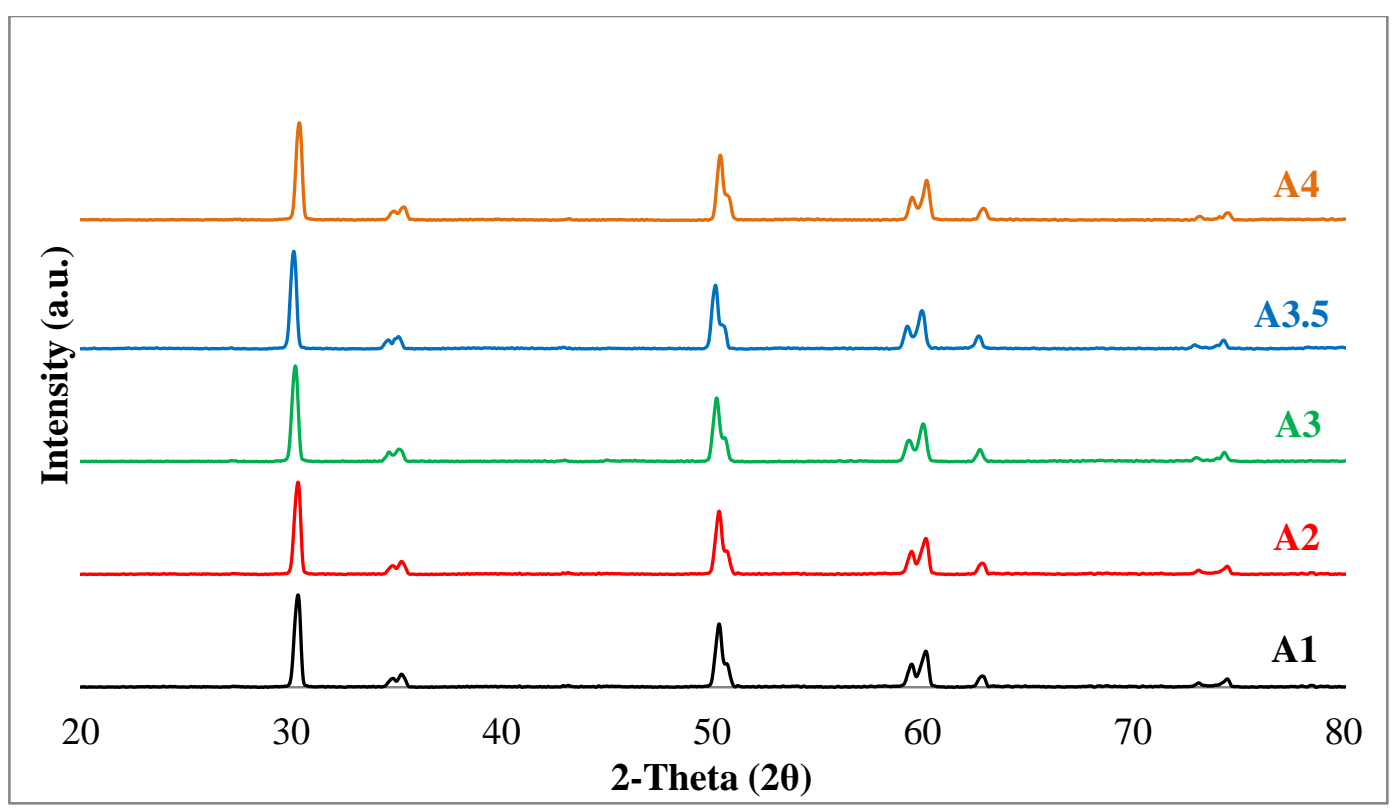

Figure 16:- XRD patterns of zirconia pellets colored with $\mathrm{A} 1-\mathrm{A} 2-\mathrm{A} 3-\mathrm{A} 3.5-\mathrm{A} 4$ coloring liquids (all peaks are tetragonal $\mathrm{ZrO}_{2}$ ).

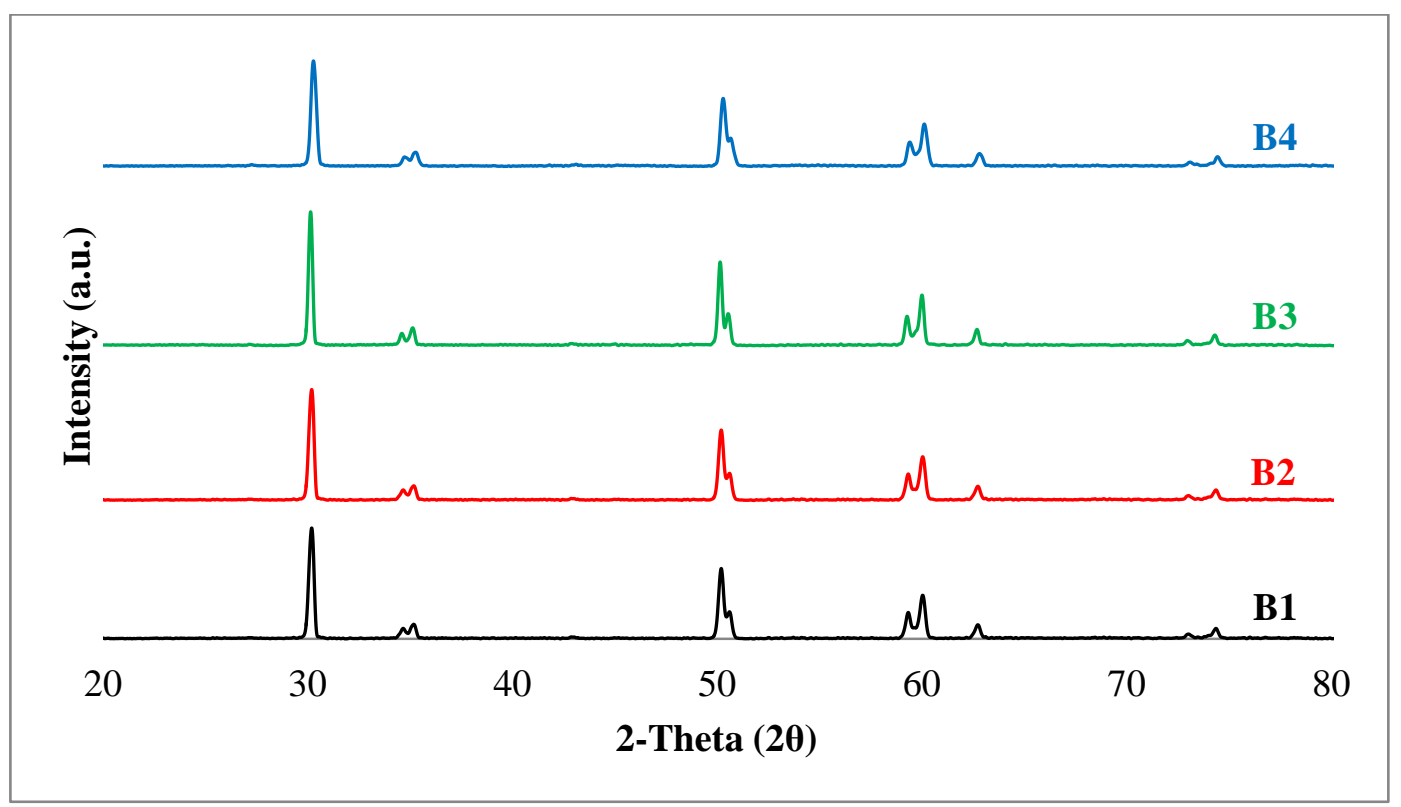

Figure 17:- XRD patterns of zirconia pellets colored with B1-B2-B3-B4 coloring liquids (all peaks are tetragonal $\left.\mathrm{ZrO}_{2}\right)$. 


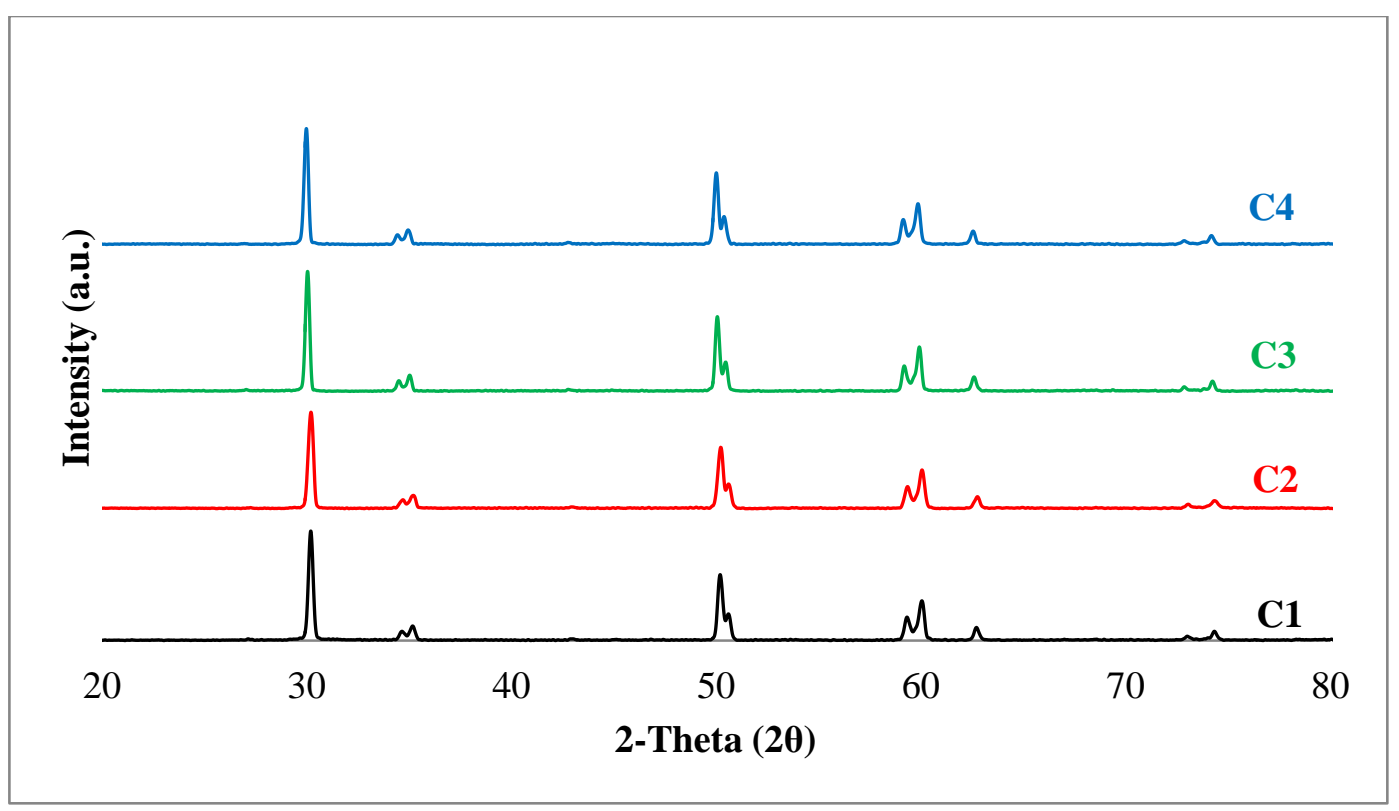

Figure 18:- XRD patterns of zirconia pellets colored with $\mathrm{C} 1-\mathrm{C} 2-\mathrm{C} 3-\mathrm{C} 4$ coloring liquids (all peaks are tetragonal $\left.\mathrm{ZrO}_{2}\right)$.

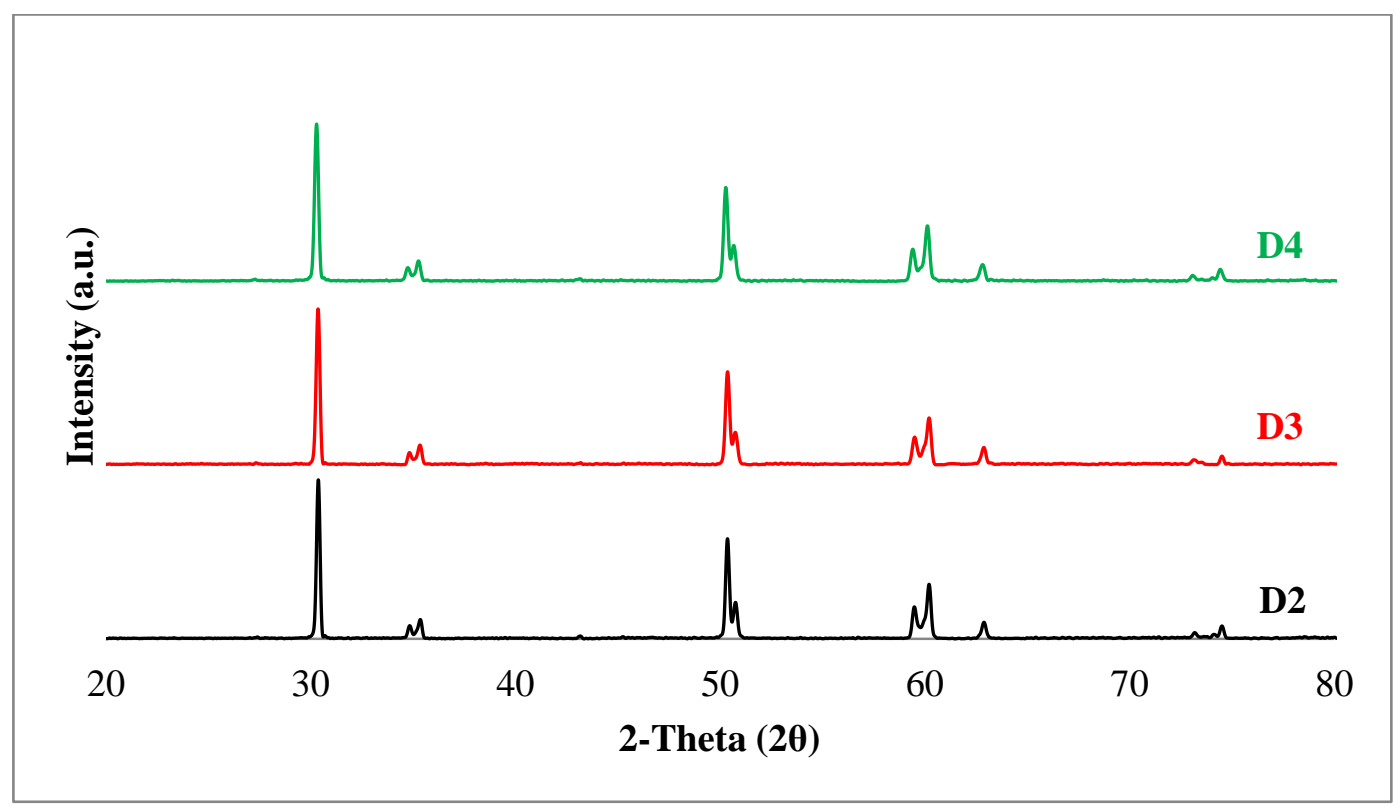

Figure 19:- XRD patterns of zirconia pellets colored with D2-D3-D4 coloring liquids (all peaks are tetragonal $\left.\mathrm{ZrO}_{2}\right)$.

Final SEM images of sintered uncolored zirconia pellets and those colored with D3 liquid with the highest coloring salt content are presented in Figure 20 and Figure 21, respectively. 


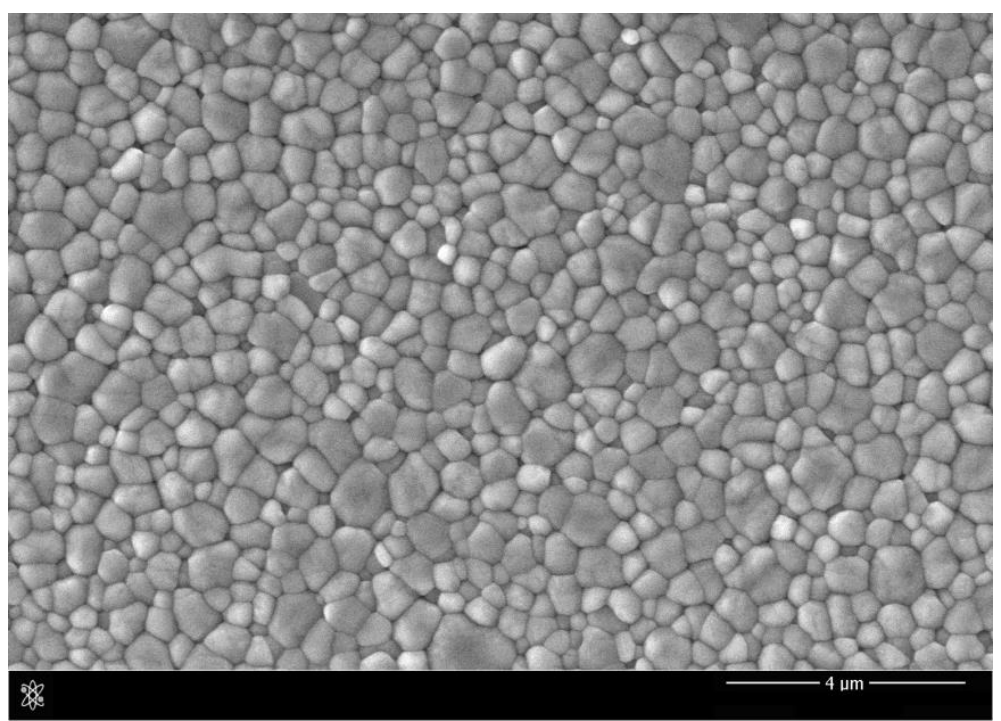

Figure 20:- Final SEM images of sintered and uncolored pellet.

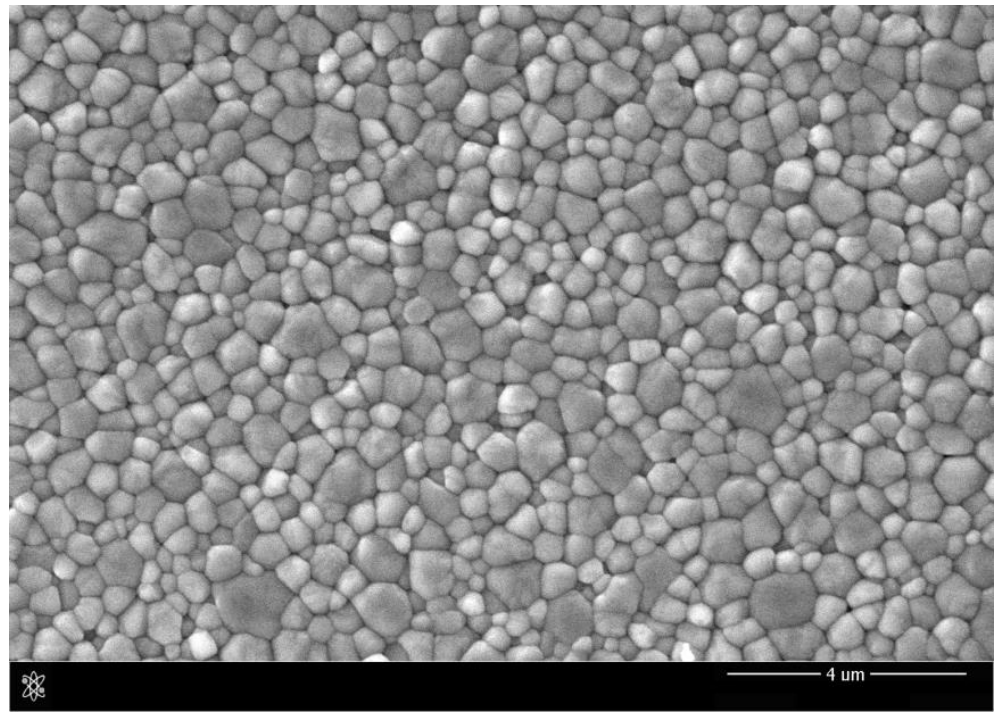

Figure 21:- Final SEM images of sintered pellet colored with D3 coloring liquid.

According to the results of SEM analysis, it is observed that uncolored and colored products are totally sintered and concentrated at $1500^{\circ} \mathrm{C}$. As a result, it was determined that the coloring liquids did not have a negative effect on the zirconia microstructure.

\section{Acknowledgement:-}

This work is supported by the Scientific Research Project Fund of Kütahya Dumlupınar Üniversitesi under the project number $2019-17$.

\section{References:-}

1. Denry, I., Kelly, R. (2008). State of the art of zirconia for dental applications. Dental Materials, 24, 299-307.

2. Nakamura, K., Harada, A., Ono, M., Shibasaki, H., Kanno, T., Niwano, Y., Adolfsson, E., Milleding, P., and Ortengren, U. (2016). Effect of low-temperature degradation on the mechanical and microstructural properties of tooth-colored 3Y-TZP ceramics. Journal of the Mechanical Behavior of Biomedical Materials, 53, 301-311.

3. Strub, J.R., Rekow, E.D., Witkowski, S. (2006). Computer-aided design and fabrication of dental restorations: current systems and future possibilities. The Journal of the American Dental Association, 137(9), 1289-1296. 
4. Maurizio, Sedda, Alessandro, Vichi, Michele, Carrabba, Alessandro, Capperucci, Chris, Louca, and Marco, Ferrari. (2015). Influence of coloring procedure on flexural resistance of zirconia blocks. Journal of Prosthetic Dentistry, 114, 98-102.

5. Hjerppe, J., Narhi, T., Froberg, K., Vallittu, P.K., and Lassila, L.V. (2008). Effect of shading the zirconia framework on biaxial strength and surface microhardness. Acta Odontologica Scandinavica, 66, 262-267.

6. Shah, K., Holloway, J.A., Denry, I.L. (2008). Effect of coloring with various metal oxides on the microstructure, color, and flexural strength of 3Y-TZP. 2008 wiley periodicals, Journal Biomedical Materials Research Part B: Applied Biomaterials, 87, 329-337.

7. Oh, G.J., Lee, K., Lee, D.J., Lim, H.P., Yun, K.D., Ban, J.S., Lee, K.K., Fisher, J.G., and Park, S.W. (2012). Effect of metal chloride solutions on coloration and biaxial flexural strength of yttria-stabilized zirconia. Metals and Materials International, 18, 805-812.

8. Tabatabaian, F., Ehsan, M., Mahasti, S., Hassan, T., and Mahshid, N. (2018). Effect of thickness of monolithic zirconia ceramic on final color. The Journal of Prosthetic Dentistry, 120, 257-62.

9. Melis Kaplan, Park, J., Kim, S.Y., Öztürk, A. (2018). Production and properties of tooth colored yttria stabilized zirconia ceramics for dental applications, Ceramics International, 44, 2413-2418.

10. Öztürk, O., Uludağ, B., Üşümez, A., Şahin, V., and Çelik, G. (2008). The effect of ceramic thickness and number of firings on the color of two all-ceramic systems, The Journal of Prosthetic Dentistry, 100(2), 99-106.

11. Kao C., Tuan W., Liu C., Chen S. (2017). Effect of iron oxide coloring agent on the sintering behavior of dental yttria-stabilized zirconia, Ceramics International, https://doi.org/10.1016/j.ceramint.2017.12.049.

12. Wen, N., Yi, Y., Zhang, W., Liu, H., Shao, L., Deng, B., and Tian, J. (2008). Study on dental colored zirconia restoration, Key Engineering Materials, 368-372, 1255-1257.

13. Lee, Y.K., Cha, H.S., Ahn, J.S. (2007). Layered color of all-ceramic core and veneer ceramics, The Journal of Prosthetic Dentistry, 97(5), 279-86.

14. Son, H.J., Kim, W.C., Jun, S.H., Kim, Y.S., Ju, S.W., and Ahn, J.S. (2010). Influence of dentin porcelain thickness on layered all-ceramic restoration color, Journal of Dentistry, 38, 71-77. 